\title{
Reconstructive Principles for the Metacarpal Hand: Case Report
}

\section{Principios reconstructivos en la mano metacarpiana: relato de caso}

\author{
Iker Miguel Escuredo ${ }^{1}$ Guillermo Ibarrondo Arzua ${ }^{1}$ Juan José García Gutierrez ${ }^{1}$ \\ 1 Plastic Aesthetic and Reconstructive Surgery Department, Cruces \\ University Hospital, Barakaldo, Bizkaia, Spain \\ Address for correspondence Iker Miguel, Cruces University Hospital, \\ Plaza de Cruces SN. 48903 Barakaldo, Bizkaia, Spain \\ Rev Iberam Cir Mano 2021;49(2):e160-e164. \\ (e-mail: ikermiguel.e@gmail.com).
}

\begin{abstract}
Keywords

- metacarpal hand

- toe-to-hand

- amputation

\section{Resumen}
Palabras Clave
- mano metacarpiana
- dedo de pie a mano
- amputación

Metacarpal hand is one of the most devastating upper-extremity lesions. We report a case of a multidigit amputation corresponding to a Wei et al. ${ }^{5}$ IA metacarpal hand in a 56 year-old-male. He underwent a sequential toe-to-hand transfer to the third and fourth radii. Reconstruction of the metacarpal hand, either in an acute or deferred presentation, must consider some reconstructive principles, including the identification of the structures to be spared and the coverage strategies for the acute stage. Toeto-hand transfer is the preferred technique when replantation is not an option. It is critical to know which structures should be transferred to which positions, as well as to adapt the reconstructive plan to the characteristics from each patient.

La mano metacarpiana es una de las lesiones más devastadoras de la extremidad superior. Nuestro caso clínico corresponde a un varón de 56 años con una amputación multidigital de la cual resultó una mano metacarpiana tipo IA de Wei. Se planteó la reconstrucción con la transferencia secuencial de dos dedos de pie a la mano en los radios tercero y cuarto. A la hora de plantearnos la reconstrucción de una mano metacarpiana, tanto de forma aguda como diferida, es necesario tener en cuenta ciertos principios reconstructivos. En primer lugar, las estructuras vitales a conservar y los métodos de cobertura en el proceso agudo. Cuando el reimplante no es posible, la transferencia de dedos del pie a la mano es la técnica de elección. Es necesario conocer qué estructuras y a qué posiciones se debe realizar la transferencia, así como adecuar las opciones a las características de cada paciente.
\end{abstract}

\section{Introduction}

Metacarpal hand is one of the most devastating upper-limb injuries, significantly impairing work and daily activities. As one of the main "social" anatomical areas of the body, this hand injury poses an esthetic problem that can stigmatize patients. ${ }^{1,2}$

The management of metacarpal hand raises several questions, and their resolution is mostly guided only by recommendations from experienced authors, since there are no received

April 20, 2021

accepted

April 30, 2021
DOI https://doi.org/ $10.1055 / \mathrm{s}-0041-1731769$. ISSN 1698-8396.

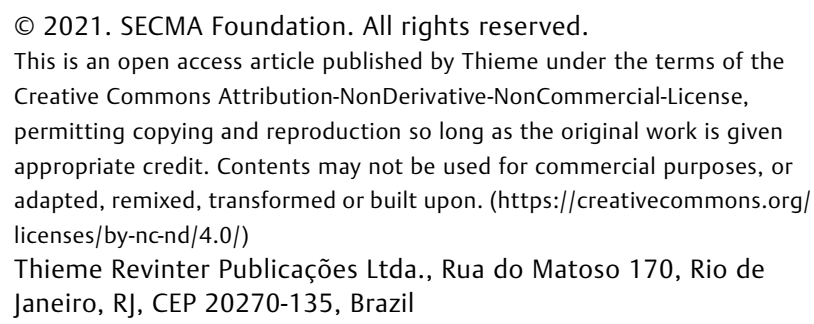


large studies with a high degree of evidence. Surgeons must consider the urgent treatment, the conditions for a satisfactory deferred surgery, and the surgical indication starting at the first contact; in addition, it is critical to know the different alternatives and to never forget that the reconstruction plan must consider the patient's requirements. ${ }^{1-6}$

\section{Case Presentation}

A 56-year-old male patient with no relevant history was referred for a consultation after regularization and direct closure of stumps from the second, third, and fourth fingers at another service, as well as the disarticulation of the fifth finger after a traumatic right-hand amputation due to an incised and blunt mechanism (lawnmower) (-Figures 1 and 2).

As a right-handed manual worker, the patient required a functional clamp with sufficient gripping force; as such, the restoration of a three-finger gripper was considered a reasonable goal.

The first toe-to-hand transfer was performed 10 months after the accident. The flap was obtained by one of the surgical teams, who dissected the first dorsal metatarsal artery up to its origin at the pedis artery and continued along the distal section of the artery. Two dorsal veins were located and dissected, in addition to the plantar collateral nerves and the flexor and extensor tendons. (-Figure 2 ). Disarticulation was carried out at the level of the metatar-

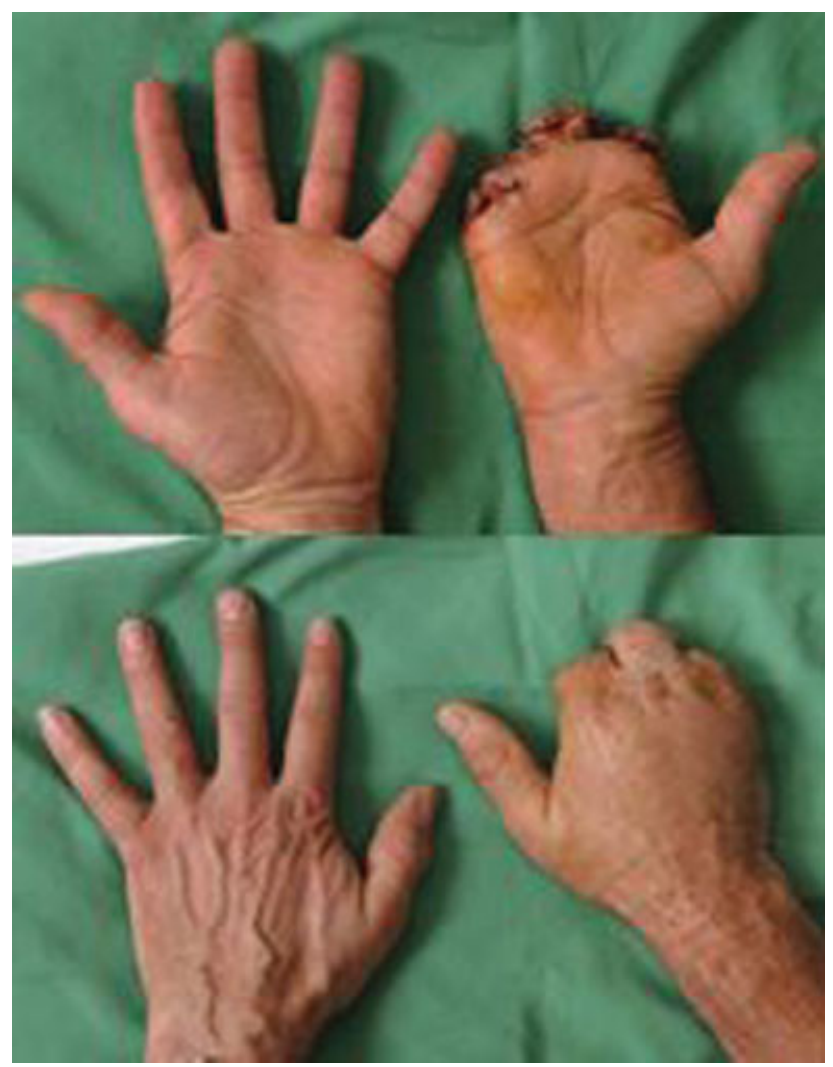

Fig. 1 Photograph of the patient during the first consultation at our service. He presents an acceptable stump for separate transfer of two toes to the radii of the third and fourth fingers. sophalangeal joint, sparing the metatarsal head. A second surgical team exposed the amputation stump, the flexor and extensor apparatus, the collateral nerves, and two subcutaneous receptor veins and the radial artery at the back of the hand. Toe osteosynthesis was performed on the remnant of the proximal phalanx of the third toe using wire cerclage. Next, the tendinous suture of both the flexor and extensor apparatus was performed. Finally, end-to-end microsurgical anastomoses of the pedis artery to the radial artery, of both dorsal veins of the foot to those of the dorsum of the hand, and of both plantar collateral nerves to the remnants of the collaterals of the third finger were performed (- Figure $\mathbf{3}$ ).

The rehabilitation process and occupational therapy began after waiting a month to achieve adequate vascular, osteosynthesis and tenorrhaphy stability. Four months after the surgery, the patient had achieved $80^{\circ}$ of flexion of the metacarpophalangeal joint, a useful grip, adequate handwriting, and the ability to grasp objects with a moderate weight (-Figures 4 and 5).

At the tenth month posttransfer, skin excesses at the junction of the proximal phalanx to the transferred finger were remodeled. After 17 months, upon patient request, the second transfer was carried out. Following the same procedure, the second toe of the right foot was transferred to the stump of the proximal phalanx of the fourth finger of the right hand. As a technical modification, arterial dissection was limited to the dorsum of the foot and performed only up to the first dorsal metatarsal artery. The arterial supply was based on this vessel, with an anastomosis to the third palmar metacarpal artery (-Figure 6). As in the first transfer, the rehabilitation process began one month after surgery, and the skin at the level of the proximal fourth phalanx was remodeled twelve months later.

After 5 years of follow-up, the patient presented a functional 3-finger gripper with adequate handwriting and flexion capacity of $80^{\circ}$ in both metacarpophalangeal joints. The grip strength is of $37 \mathrm{~kg}$ in the left (unaffected) hand and of $12.2 \mathrm{~kg}$ in the right hand. The two-point tactile discrimination is of $6 \mathrm{~mm}$ and $10 \mathrm{~mm}$ for both ulnar and radial collateral

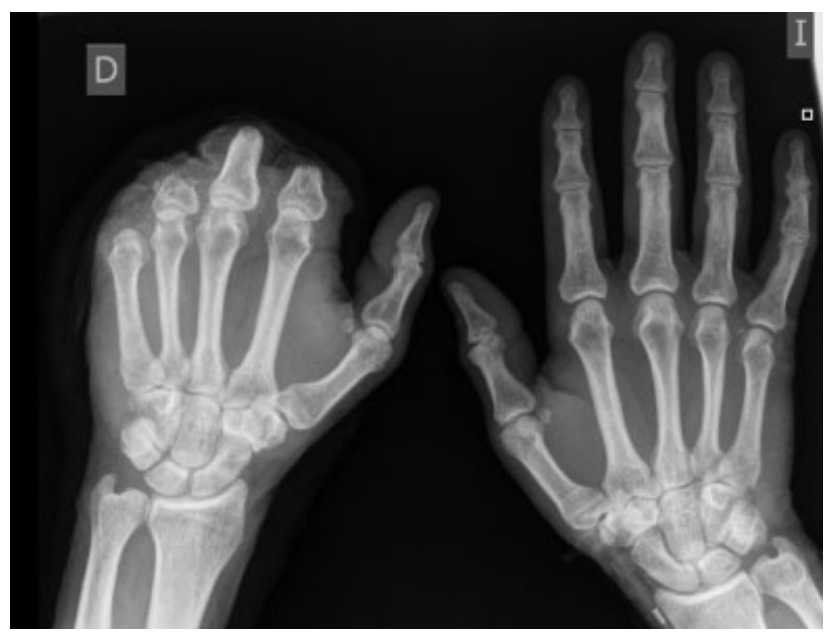

Fig. 2 Radiograph before the first transfer. 


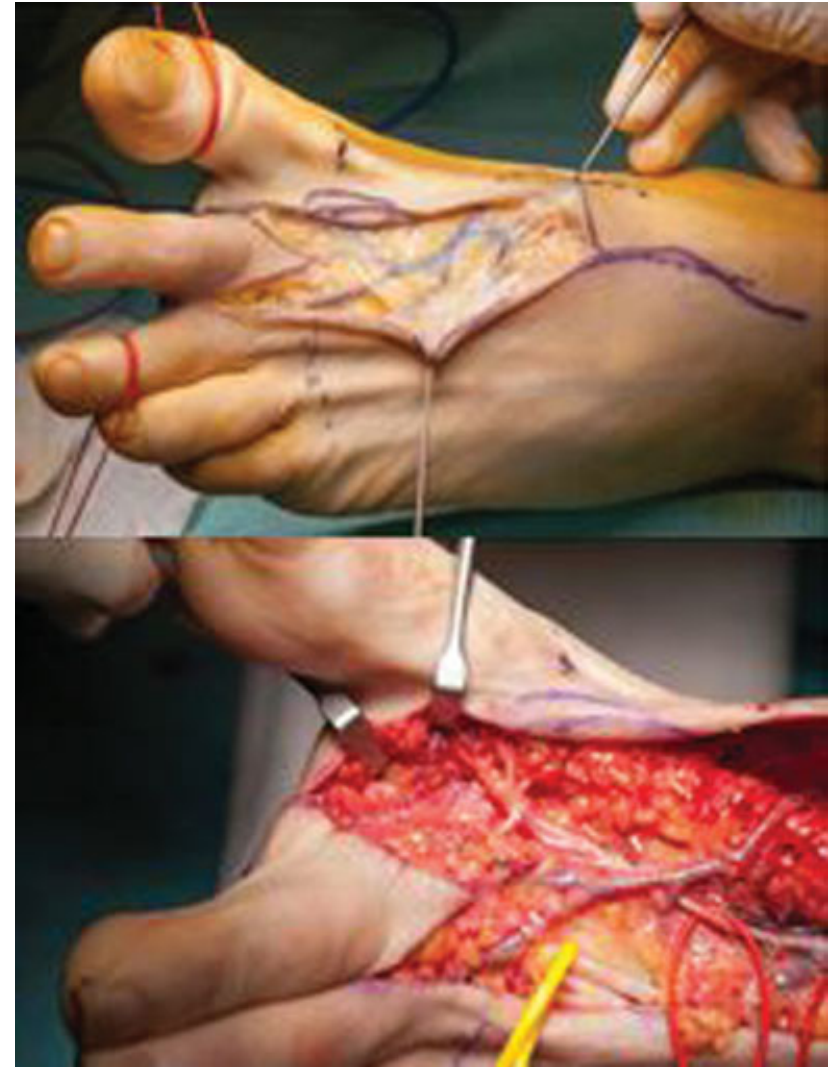

Fig. 3 Intraoperative detail during the harvesting of the second toe of the left foot. The dissection of the superficial venous network on which the venous drainage of the flap will be based is on the left side. The dorsal vein, first dorsal metatarsal artery (red vessel loop) and extensor tendon (yellow vessel loop) are at the right side of the image.

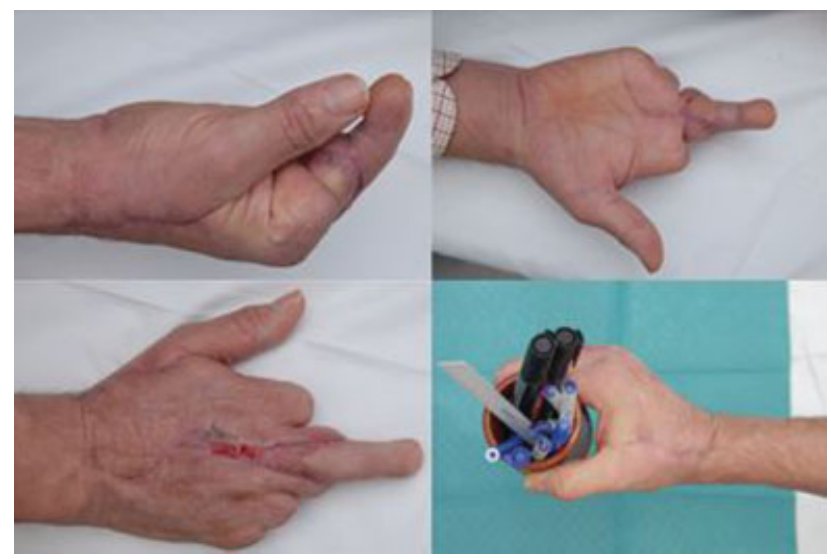

Fig. 4 Outcomes two months after the first transfer.

nerve regions from the third and fourth fingers respectively. The patient has no gait disturbances ( $\mathbf{- F i g u r e s} \mathbf{7}$ and $\mathbf{8}$ ).

\section{Discussion}

The most accepted definition for the term metacarpal hand was proposed by Wei et al. ${ }^{5}$ in 1997 . According to these authors, this term describes a hand that has suffered a traumatic amputation of the triphalangeal fingers, not maintaining a minimum acceptable length for any of them, with or

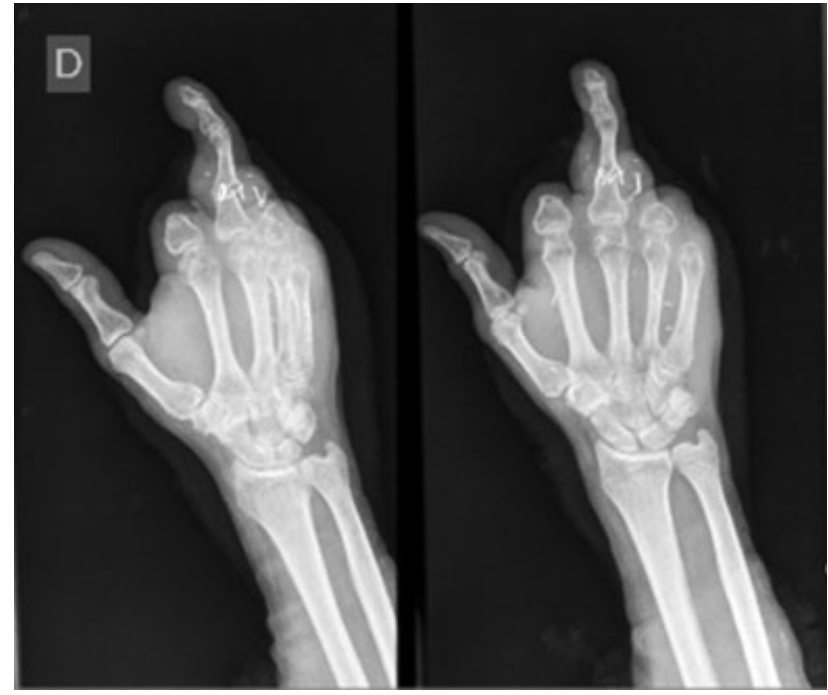

Fig. 5 Radiograph after the first transfer.

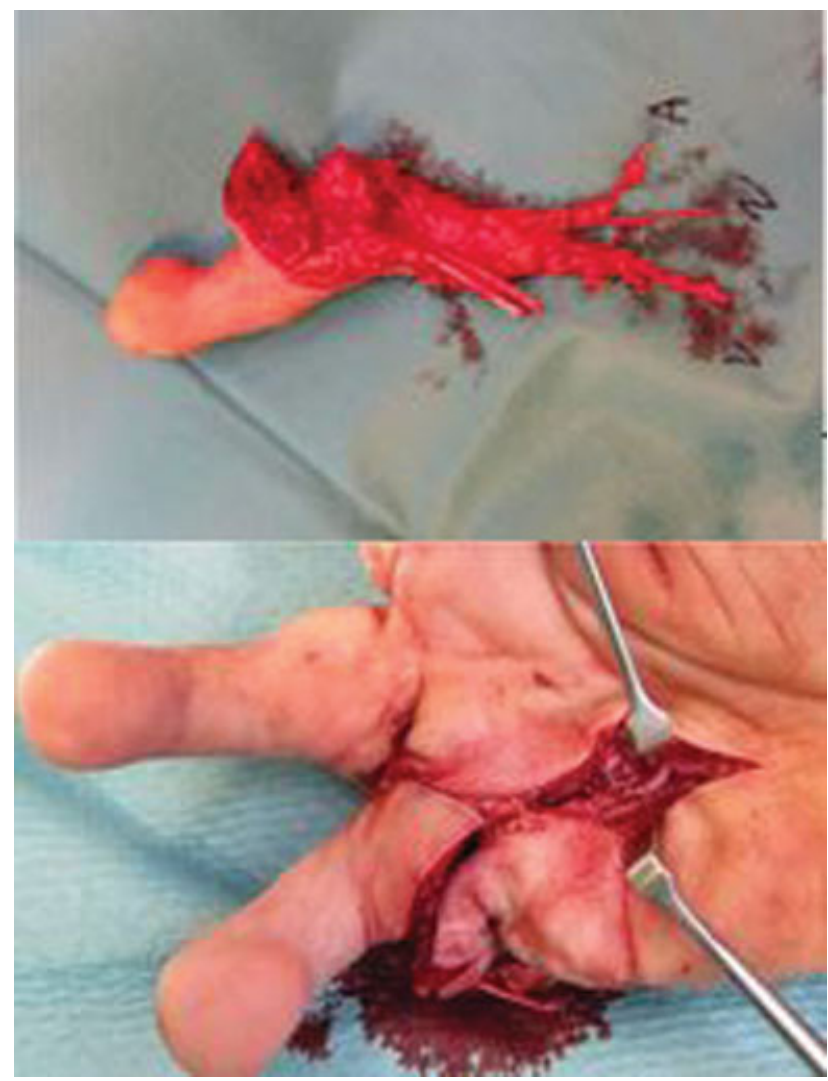

Fig. 6 Images of the transfer of the second toe from the right foot to the fourth radius. At the top, the figure shows (up) the free flap and its artery (A), the planar nerve $(\mathrm{N})$, and the dorsal vein (V). (Down) Image from the transfer after arterial anastomosis.

without thumb involvement. In addition, these authors proposed that a metacarpal hand with an adequate thumb length (usually intact) would be further classified as "type I"; in contrast, a "type II" metacarpal hand presents an inadequate thumb length. The minimum acceptable length in an amputation spares at least the proximal half of the proximal phalanx in triphalangeal fingers and the complete first 


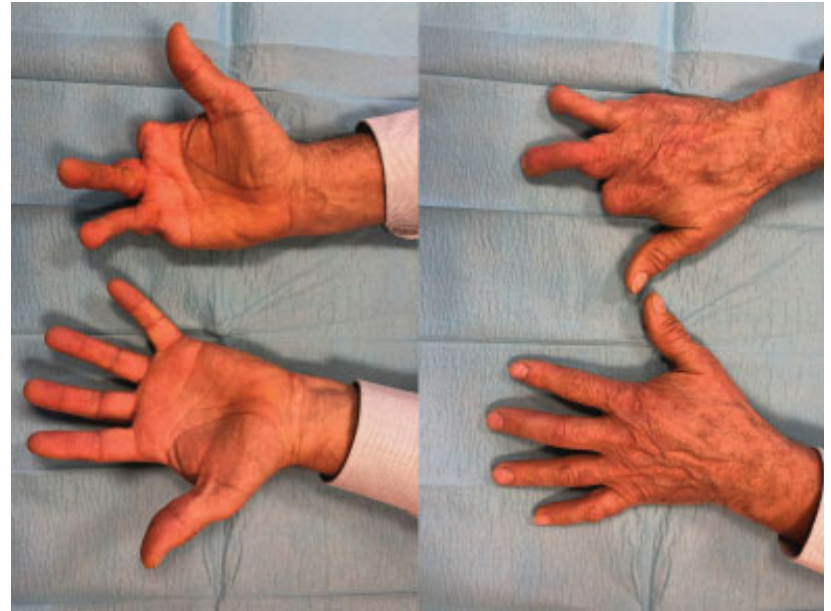

Fig. 7 Outcomes five years after the second transfer.

phalanx of the thumb. ${ }^{1,2,4-6}$ Each type is subdivided into different categories depending on the level. In type IA, amputation occurs distal to the metacarpophalangeal joint. In type IB, amputation occurs at the metacarpophalangeal articular surface. In type IC, amputation is at the metacarpal itself. In type IIA, thumb amputation is distal to the neck of the first metacarpal bone. In type IIB, it occurs at the level of the metacarpophalangeal joint, with no injury to the articular metacarpal cartilage; in type IIC, there is cartilage injury, or the amputation occurs at the first metacarpal bone. In type IID, the trapeziometacarpal joint is destroyed. ${ }^{2,4-7}$

The reconstructive process aims to obtain a hand capable of gripping and grasping objects, with virtually normal sensitivity and esthetics. ${ }^{1,2}$ This requires a thumb with an acceptable opposing function, or at least fixed in abduction and opposition to function passively when grasping objects. In contrast, the restoration of a strong gripper requires the restoration of two contiguous digits opposable to the thumb. These principles can guide the selection of the most appropriate reconstructive procedure. However, this decision must be adapted to the patient's occupation, daily activity, degree of motivation, and esthetic concerns. ${ }^{1-6}$

The initial care should focus on tissue preservation and skin coverage, but the former cannot be conditioned by the latter. An effort is made to preserve certain structures that will condition the reconstruction outcome, as well as to lower the morbidity at the donor area, ${ }^{2}$ including neurovascular structures, metacarpophalangeal joints, the trapeziometacarpal joint, and thenar muscles. If any of these structures were vital, their regularization to enable the coverage with local tissues would be contraindicated. Most authors $^{1,4,5}$ prefer a coverage with a pedicled inguinal flap, a fast and safe technique, with the disadvantage of requiring a second time for pedicle section and flap remodeling, in addition to keeping the hand joined to the inguinal region. Other authors ${ }^{1}$ advocate the use of free flaps, such as those from the gracilis muscle, a more complex technique but with none of these disadvantages.

Replantation viability must be assessed after debridement. It is not uncommon for the viability to be low due to

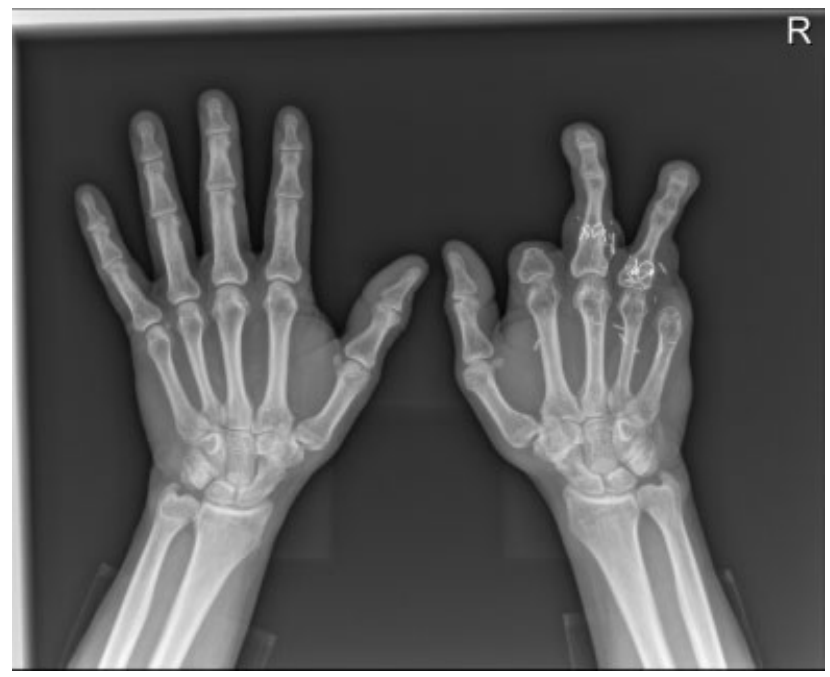

Fig. 8 Radiograph five years after the second transfer.

the highly-destructive mechanisms causing these injuries. If any of the fingers is viable, a heterotopic replantation should be considered. ${ }^{3}$ The next alternative is toe-to-hand transfer; although it can be performed in an urgent setting, it is mostly deferred and performed with adequate surgical planning in a referral center.

The classic recommendation regarding the timing of the free transfer is when wound healing is complete, with no infection or other concomitant complications. ${ }^{2}$ In contrast, delaying the definitive reconstruction helps to detect nonviable structures spared by the initial urgent surgery, either due to lack of vitality or functional impairment. ${ }^{8}$ However, recovery time increases significantly. Some authors $1,2,8,9$ recommend immediate transfer if replantation is not possible. Several studies ${ }^{1,2,8,9}$ have not detected an increase in the rates of complications, revision, or reconstruction failure. However, since these reports are from case-control studies based on small series, their results should be considered with caution. $^{10}$

The next question is the number of fingers to transfer. This is determined by the number of fingers required to achieve the reconstructive goal: a strong, sensitive, functional, and esthetic three-finger gripper. The main limitation is determined by the morbidity of the donor area. For the type-I metacarpal hand, the transfer of two triphalangeal fingers of the foot is usually enough. 1,2,4,5 Type-II metacarpal hand requires a functional thumb, usually to transfer the first toe to that position. In turn, two triphalangeal fingers are required for the transfer. The transfer of a single triphalangeal finger in type-I metacarpal hand or a thumb and a triphalangeal finger in type-II metacarpal hand is an option for patients with a limited donor site due to previous amputations or bilateral cases. ${ }^{2,6}$

The transfer of two second toes to the third and fourth radii allows a correct balance between the gripper capacity and the grasp of objects and tools., ${ }^{2,4}$ Toe transfer to the fourth and fifth radii is warranted in patients with high demand for grasp tools (construction workers, carpenters etc.) and no need for a precise grip. 
The foot structures to be transferred vary depending on the level of the injury. For type-IA metacarpal hand, a transfer including three phalanges alone is enough. TypeIB requires the inclusion of the metatarsophalangeal joint with a capsule for correct articular function with the metacarpal bone. ${ }^{2}$ Type-IC requires a transmetatarsal transfer, which can alter the plantar arch and interfere with gait. Simple or two-finger transfer combined with a single pedicle is performed depending on the level of the amputation; the former is suitable for those cases in which the interdigital commissure is preserved, whereas the latter is indicated when the interdigital commissure has been lost. ${ }^{1,2,4-6} \mathrm{Re}-$ construction of the first finger complies with the same principles: usually the transfer of the first toe, which requires an opponensplasty for type-IIC metacarpal hand. For typeIID, the reconstructed thumb is submitted to an arthrodesis in functional position to enable grasping and clamping. ${ }^{2}$ The second, third, and fourth fingers can be used as triphalangeal finger donors. When used separately, one toe can be obtained from each foot to not accumulate all the morbidity in a single limb. It is often recommended to keep at least three toes on each foot, preferably the first, fourth, and fifth toes. $^{4}$

Following the same principles, a patient with a bilateral Wei et al. ${ }^{5}$ type-II amputation would require the transfer of both halluces and two additional toes from each foot, resulting in unacceptable morbidity. In such cases, the dominant hand is restored with one thumb and two triphalangeal toes from one foot, while the non-dominant hand receives a triphalangeal toe to restore the thumb and only one more transfer, preferably to restore the third radius. ${ }^{2,4,6}$

\section{Conclusion}

Metacarpal hand is a severe upper-limb condition, potentially equivalent to the amputation of the whole hand in terms of functional aspects. This entity can be approached by different surgical teams for initial care and delayed reconstruction. Therefore, it is extremely important to know the reconstructive principles and keep them in mind when performing urgent surgery. If replantation is not feasible, the procedure of choice is the transfer of toes to the hand. The goal of the reconstruction is to obtain an endto-end three-finger gripper. The morbidity in the donor area must be balanced with the benefit obtained from the reconstruction; in addition, the number of fingers to be transferred and their position must be individualized for each case.

\section{References}

1 del Piñal F. Severe mutilating injuries to the hand: guidelines for organizing the chaos. J Plast Reconstr Aesthet Surg 2007;60(07): 816-827

2 Wallace CG, Wei FC. Posttraumatic finger reconstruction with microsurgical transplantation of toes. Hand Clin 2007;23(01): 117-128

3 Kokkoli E, Spyropoulou GA, Shih HS, Feng GM, Jeng SF. Heterotopic Procedures in Mutilating Hand Injuries: A Synopsis of Essential Reconstructive Tools. Plast Reconstr Surg 2015;136(05): 1015-1026

4 ALDeek NF, Lin YT, Wei FCNF AL. Metacarpal-Like and Metacarpal Hand. Hand Clin 2016;32(04):549-554

5 Wei FC, el-Gammal TA, Lin CH, Chuang CC, Chen HC, Chen SH. Metacarpal hand: classification and guidelines for microsurgical reconstruction with toe transfers. Plast Reconstr Surg 1997;99 (01):122-128

6 Wei FC, Lutz BS, Cheng SL, Chuang DC. Reconstruction of bilateral metacarpal hands with multiple-toe transplantations. Plast Reconstr Surg 1999;104(06):1698-1704

7 Lin $\mathrm{CH}$, Hu TL, Lin CH. Split second- and third-toe transplantation in mutilating-hand-injury reconstruction. Ann Plast Surg 2008; 60(03):267-271

8 Yim KK, Wei FC, Lin CH. A comparison between primary and secondary toe-to-hand transplantation. Plast Reconstr Surg 2004;114(01):107-112

9 Woo SH, Kim JS, Seul JH. Immediate toe-to-hand transfer in acute hand injuries: overall results, compared with results for elective cases. Plast Reconstr Surg 2004;113(03):882-892

10 Lin YT, Su ST, Lo S, Hu CH, Lin $\mathrm{CH}$, Wei FC. Risk factors for reexploration in toe-to-hand transfer: a multivariate analysis of 363 cases. Plast Reconstr Surg 2015;135(02):501-506 